\title{
Prognosis prediction or treatment allocation?
}

\author{
Ryosuke Tateishi $^{1}$ (B)
}

Received: 30 March 2021 / Accepted: 24 April 2021 / Published online: 9 May 2021

(c) Asian Pacific Association for the Study of the Liver 2021

Keywords Cancer staging $\cdot$ Tumor biology $\cdot$ Technical feasibility

\author{
Abbreviations \\ BCLC Barcelona Clinic Liver Cancer \\ HCC Hepatocellular carcinoma \\ TACE Transarterial chemoembolization \\ TNM Tumor node metastasis \\ UICC Union for International Cancer Control
}

The TNM classification scheme of the Union for International Cancer Control (UICC) was developed in the 1940s by French surgeon Pierre Denoix [1]. The cancer stage is determined using the TNM factors: "T" stands for tumor extension, "N" for regional lymph node involvement, and " $\mathrm{M}$ " for distant metastasis. Staging had been based on the probability of cure when complete surgical resection of cancer cells was the only effective treatment strategy. Stage 1, localized cancer, indicates that the cancer has the highest probability of cure. However, the presence of distant metastasis (M1) indicates no probability for cure via surgical treatment. All cancer types that are M1 regardless of the status of the other two factors are classified as stage 4 .

The TNM classification is widely used to classify most solid cancers. The exception is hepatocellular carcinoma (HCC), in which liver function, along with tumor extension, is a strong determinant of prognosis because $\mathrm{HCC}$ generally arises from chronic liver disease or cirrhosis. The Okuda staging system was the first integrated staging system for predicting the prognosis of HCC. The system uses tumor extension, the presence of ascites, and the levels of albumin and bilirubin [2]. In the Okuda staging system, one point is assigned to each factor and the total number of points is used to predict the prognosis. The Okuda system was followed by

Ryosuke Tateishi

tateishi-tky@umin.ac.jp

1 Department of Gastroenterology, Graduate School of Medicine, The University of Tokyo, 7-3-1 Hongo, Bunkyo-ku, Tokyo 113-8655, Japan other systems intended to be more precise in predicting the prognosis for patients with early-stage HCC according to advances in diagnostic procedures and the establishment of surveillance of high-risk populations [3-6].

Although the Barcelona Clinic Liver Cancer (BCLC) staging classification system functions as a prognosis predictor, it also uses an algorithm to allocate treatment for HCC on the basis of classification factors, such as tumor size and number, vascular invasion, distant metastasis, Child-Pugh class, and portal hypertension [7]. With a few exceptions, many international guidelines have adopted this type of treatment allocation system [8-10].

Treatment algorithm and prognosis prediction of $\mathrm{HCC}$ are frequently confused. Whereas the indications for the treatment of HCC are based on the technical feasibility of the treatment, the prognosis prediction is based on the biological aggressiveness of the tumor. The two standpoints can be confused by some because the stratification factors are also prognostic factors (Table 1). For example, the criteria of a tumor being $\leq 3 \mathrm{~cm}$ and no more than 3 nodules originated with the use of ethanol injection because of its feasibility in controlling local tumors. The expanded version of these criteria, known as the Milan criteria, is used to determine the indication for liver transplantation. Because tumor extension within the liver does not affect the technical difficulty of treatment, the biologically aggressiveness outside of the criteria determines the contraindication for liver transplantation [11].

The BCLC system has five stages, with each stage recommending first-line therapy. The recommendation is based on the concept that more radical treatment is preferred if a patient is in better condition with respect to tumor progression and liver function reserve. Therefore, the intermediate stage (stage B) is defined as exclusion from the early stage (stage A). As a result, the prognosis for stage B disease is quite diverse and several sub-classifications for stage B $\mathrm{HCC}$, for which trans-arterial chemoembolization (TACE) is recommended as the first-line treatment, have been proposed 
Table 1 Biological and technical implications involved in stratification factors for classifying hepatocellular carcinoma

\begin{tabular}{lll}
\hline Factor & Biological implication & Technical feasibility \\
\hline $\begin{array}{l}\text { Single nodule }>5 \mathrm{~cm} \\
2 \text { or } 3 \text { nodules }>3 \mathrm{~cm}\end{array}$ & Probability of tumor cells migrating into systemic circulation & Ablation not feasible \\
& High probability of intrahepatic dissemination of tumor & Ablation not feasible \\
$>3$ nodules & Unresectable depending on tumor distribution \\
Tumor $>10 \mathrm{~cm}$ & Rapid proliferation & Ablation not feasible \\
Macrovascular invasion & Migration of tumor cells into systemic circulation almost certain & Unresectable in most cases \\
Extrahepatic metastasis & Definite sign of systemic disease & Unresectable depending on tumor location \\
\hline
\end{tabular}

for better prediction of a prognosis and optimal treatment allocation $[12,13]$.

In this issue of Hepatology International, Lin et al. propose a new sub-classification stage for BCLC stage $\mathrm{C}$ that includes tumor size $<10 \mathrm{~cm}$, extrahepatic metastasis, macrovascular invasion, Child-Pugh class, and age $>75$ years based on survival analysis [14]. This new sub-classification stage had good prognosis discriminatory ability for BCLC stage $\mathrm{C}$ patients in both domestic and international validation cohorts. The authors propose a new treatment algorithm for BCLC stage C patients based on this sub-classification stage. However, they ignored the technical aspects of the stratification factors. For example, patients with distant metastasis and classified as C2 if they have small tumors without macrovascular invasion and Child-Pugh A liver function are contraindicated for any of the loco-regional therapies, including hepatic resection, radiofrequency ablation, and TACE. On the other hand, hepatic resection rather than systemic therapy may provide long-term survival in some stage $\mathrm{C} 2$ patients with localized vascular invasion and preserved liver function [15].

Although macrovascular invasion and extrahepatic metastasis have a similar prognostic impact on a patient and thus are often confused with each other, they have different biological implications. Whereas macrovascular invasion indicates an invasive tumor phenotype, extrahepatic metastasis suggests, in addition to invasive feature, the loss of intracellular cohesiveness and the ability of the tumor to proliferate in a different environment than the primary site. The difference between the biological phenotypes may affect clinical decisions with respect to the use of systemic therapies and the selection of loco-regional treatments.

The advent of next-generation sequencing has enabled the molecular sub-classification of HCC based on mutational, transcriptomic, and epigenetic characteristics [16]. Understanding the comprehensive biological features of HCC will help tailor the treatment of each patient in the future. However, currently, there are no specific genetic findings that ultimately contraindicate hepatic resection. On the other hand, the presence of distant metastasis is still the most decisive factor in the choice of treatment, as Denoix suggested 70 years ago, proving that findings based on the insights of clinicians also have long-lasting value. In conclusion, treatment allocation and prognosis should be considered separately. Some treatment-specific factors should not be combined when developing a treatment algorithm.

\section{References}

1. The TNM Classification of Malignant Tumours, 8th edn.

2. Okuda K, Ohtsuki T, Obata H, Tomimatsu M, Okazaki N, Hasegawa H, Nakajima Y, Ohnishi K. Natural history of hepatocellular carcinoma and prognosis in relation to treatment. Study of 850 patients. Cancer. 1985;56:918-28.

3. The Cancer of the Liver Italian Program (CLIP) investigators. A new prognostic system for hepatocellular carcinoma: a retrospective study of 435 patients. Hepatology. 1998;28:751-5.

4. Chevret S, Trinchet JC, Mathieu D, Rached AA, Beaugrand $\mathrm{M}$, Chastang C. A new prognostic classification for predicting survival in patients with hepatocellular carcinoma. Groupe dEtude et de traitement du carcinome hepatocellulaire. J Hepatol. 1999;31:133-41.

5. Leung TW, Tang AM, Zee B, Lau WY, Lai PB, Leung KL, Lau JT, Yu SC, Johnson PJ. Construction of the Chinese university prognostic index for hepatocellular carcinoma and comparison with the TNM staging system, the Okuda staging system, and the Cancer of the Liver Italian Program staging system: a study based on 926 patients. Cancer. 2002;94:1760-9.

6. Tateishi R, Yoshida H, Shiina S, Imamura H, Hasegawa K, Teratani T, Obi S, Sato S, Koike Y, Fujishima T, Makuuchi M, Omata M. Proposal of a new prognostic model for hepatocellular carcinoma: an analysis of 403 patients. Gut. 2005;54:419-25.

7. European Association for the Study of the Liver. EASL clinical practice guidelines: management of hepatocellular carcinoma. J Hepatol. 2018;69:182-236.

8. European Association for the Study of the Liver. easl clinical practice guidelines: management of hepatocellular carcinoma. J Hepatol. 2018;69:182-236.

9. Marrero JA, Kulik LM, Sirlin CB, Zhu AX, Finn RS, Abecassis MM, Roberts LR, Heimbach JK. Diagnosis, staging, and management of hepatocellular carcinoma: 2018 practice guidance by the american association for the study of liver diseases. Hepatology. 2018;68:723-50.

10. Omata M, Cheng AL, Kokudo N, Kudo M, Lee JM, Jia J, Tateishi R, Han KH, Chawla YK, Shiina S, Jafri W, Payawal DA, Ohki 
T, Ogasawara S, Chen PJ, Lesmana CRA, Lesmana LA, Gani RA, Obi S, Dokmeci AK, Sarin SK. Asia-Pacific clinical practice guidelines on the management of hepatocellular carcinoma: a 2017 update. Hepatol Int. 2017;11:317-70.

11. Mazzaferro V, Regalia E, Doci R, Andreola S, Pulvirenti A, Bozzetti F, Montalto F, Ammatuna M, Morabito A, Gennari L. Liver transplantation for the treatment of small hepatocellular carcinomas in patients with cirrhosis. N Engl J Med. 1996;334:693-9.

12. Bolondi L, Burroughs A, Dufour JF, Galle PR, Mazzaferro V, Piscaglia F, Raoul JL, Sangro B. Heterogeneity of patients with intermediate (BCLC B) Hepatocellular Carcinoma: proposal for a subclassification to facilitate treatment decisions. Semin Liver Dis. 2012;32:348-59.

13. Kudo M, Arizumi T, Ueshima K, Sakurai T, Kitano M, Nishida N. Subclassification of BCLC B stage hepatocellular carcinoma and treatment strategies: proposal of modified bolondi's subclassification (Kinki Criteria). Dig Dis. 2015;33:751-8.

14. Lin CW, Chen YS, Lo GH, Wu TC, Yeh JH, Yeh ML, Dai CY, Huang JF, Chuan WL, Roberts LR, Jun DW, Toyoda H, Yasuda
S, Nguyen MH, Yu ML. Resubclassification and clinical management for Barcelona Clinic Liver Cancer Stage $\mathrm{C}$ hepatocellular carcinoma: an international cohort. Hepatol Int. 2021;19:10-3.

15. Kokudo T, Hasegawa K, Matsuyama Y, Takayama T, Izumi N, Kadoya M, Kudo M, Ku Y, Sakamoto M, Nakashima O, Kaneko S, Kokudo N, Liver Cancer Study Group of J. Survival benefit of liver resection for hepatocellular carcinoma associated with portal vein invasion. J Hepatol. 2016;65:938-43.

16. Rebouissou S, Nault JC. Advances in molecular classification and precision oncology in hepatocellular carcinoma. J Hepatol. 2020;72:215-29.

Publisher's Note Springer Nature remains neutral with regard to jurisdictional claims in published maps and institutional affiliations. 